\title{
Recombinant Human Adenovirus with Rat MIP-2 Gene Insertion Causes Prolonged PMN Recruitment to the Murine Brain
}

\author{
M. D. Bell' ${ }^{1}$, D. D. Taub' ${ }^{2}$, S. J. Kunkel ${ }^{3}$, R. M. Strieter ${ }^{3}$, R. Foley ${ }^{4}$, J. Gauldie ${ }^{4}$ and V. H. Perry ${ }^{1}$ \\ ${ }^{1}$ Department of Pharmacology, University of Oxford, Oxford OX1 3QT, UK \\ ${ }^{2} \mathrm{NCl}$ Cancer Research and Development Center, SAIC-Frederick, Maryland, USA \\ ${ }^{3}$ Department of Pathology, University of Michigan, Ann Arbor, Michigan, USA \\ ${ }^{4}$ Department of Pathology, McMaster University, Hamilton, Ontario, Canada
}

Keywords: inflammation, chemokines, tachyphylaxis, blood-brain barrier

\begin{abstract}
Single injections of recombinant cytokines/chemokines into tissue have provided insights into their possible roles during the inflammatory response. Adenoviral technology may allow us to mimic the in vivo situation more closely, with protein generated in a continuous but transient fashion. Replication-deficient human type 5 adenovirus containing a rat macrophage inflammatory protein-2 (MIP-2) gene insertion and cytomegalovirus promoter was injected into the mouse brain to investigate the inflammatory response to continuous overproduction of MIP-2. Adenovirus with a $L a c Z$ gene insertion expressing $\beta$-galactosidase was used as a control. At doses of $10^{4}$ to $10^{7}$ plaque-forming units, a minimal inflammatory response was detected to the LacZ virus, with leukocyte recruitment that was restricted to the injection site. A dose of $10^{7}$ plaque-forming units of both the $L a C Z$ and the MIP-2 vector produced extensive transgene product expression that persisted for at least 7 days. Astrocytes, recognized by their morphology, were the predominant cell type expressing MIP-2 and $\beta$-galactosidase. A dose of $10^{7}$ plaque-forming units of MIP-2 vector caused dramatic polymorphonuclear leukocyte (PMN) recruitment to the brain parenchyma after 2 days. PMN recruitment was still observed after 4 and 7 days, but had become more localized to the injection site and was associated with numerous foam-like macrophages. At both 2 and 7 days the blood-brain barrier was breached in the region of leukocyte recruitment. Despite the extent of leukocyte recruitment there were no overt signs of neuronal degeneration or demyelination. Our findings demonstrate that continuous production of MIP-2 in the CNS results in persistent PMN recruitment to the brain parenchyma with no evidence of tachyphylaxis. The lack of PMN recruitment to the brain parenchyma following CNS injury may be a result of deficient production of PMN chemoattractants.
\end{abstract}

\section{Introduction}

Previous studies have demonstrated that the CNS is resistant to polymorphonuclear leukocyte (PMN) recruitment following the injection of various proinflammagens or during acute neuronal degeneration (Andersson et al., 1991, 1992a, b). Similarly, in many neurological diseases, such as multiple sclerosis, experimental allergic encephalomyelitis, Alzheimer's disease and Parkinson's disease, PMNs appear to be excluded from the brain parenchyma and leukocyte recruitment is restricted to T-cells and monocytes (Traugott et al., 1983; Itagaki et al., 1988; McGeer et al., 1994). Macrophage inflammatory protein2 (MIP-2) is a rodent $\alpha$-chemokine with potent chemoattractant activity for PMNs in vitro and in vivo (Wolpe et al., 1989; Wolpe and Cerami, 1989). We have recently demonstrated that recombinant murine MIP-2 and human interleukin (IL)-8 will produce dramatic PMN recruitment to the murine brain parenchyma when injected intracranially (M. D. Bell, D. D. Taub and V. H. Perry, submitted for publication). In vivo, cytokines and chemoattractants will be produced continuously at high concentrations into the local environment. Single bolus injections of recombinant proteins may not accurately reflect their roles during tissue inflammation. In contrast, continued exposure of the environment to chemoattractants such as MIP-2 may result in rapid tachyphylaxis.

The biological function of cytokines or chemokines may be examined in a more physiological setting using a novel delivery system. Viruses may be used as vectors to transfer protein genes or cDNA into target tissue. Infection of rapidly dividing cells has been successfully achieved using retroviral vectors (Rosenberg et al., 1988; Wolff et al., 1989). These, however, are unable to infect fully differentiated cells with low turnover, such as glial cells and neurons of the brain. Adenoviruses, on the other hand, are capable of infecting postmitotic cells such as hepatocytes (Jaffe et al., 1992; Herz and Gerard, 1993), myotubules (Quantin et al., 1992; Stratford-Perricaudet et al., 1992), endothelial cells (Lemarchand et al., 1992) and lung epithelial cells (Rosenfeld et al., 1992; Xing et al., 1994). Recently, adenovirus-mediated gene transfer has been applied to the CNS where

Correspondence to: V. H. Perry, as above 
infection of glial cells (Akli et al., 1993; Le Gal La Salle et al., 1993), ependymal cells (Akli et al., 1993; Bajocchi et al., 1993) and neurons (Akli et al., 1993; Davidson et al., 1993; Le Gal La Salle et al., 1993) has been demonstrated with more prolonged transgene expression than with infection in other tissues.

The use of human recombinant type 5 adenoviruses expressing rodent IL-6 and IL-2 genes has been shown previously (Braciak et al., 1993; Xing et al., 1994; Addison et al., 1995). In the current study, we have used the same vector system with a rat MIP-2 gene insertion. We have examined the biological effect of prolonged but transient expression of the transgene in the CNS, mimicking an in vivo inflammatory episode. A vector with a $L a c Z$ gene insertion coding for $\beta$-galactosidase was used as a control to examine background inflammatory responses to the virus itself.

\section{Materials and methods}

\section{Recombinant adenovirus vectors}

The construction of similar recombinant human type 5 adenovirus has been well characterized previously (Braciak et al., 1993). Viruses were made replication-deficient by deleting E1 and rat MIP-2 cDNA inserted into the $\mathrm{E} 3$ region of the genome. Rat $M I P-2$ has previously been cloned and has a base sequence homology of $90.3 \%$ with murine MIP-2 (Driscoll et al., 1995). A human cytomegalovirus promoter and SV40 polyadenylation sequence were inserted upstream and downstream of the MIP-2 cDNA respectively (Ad5MIP-2). Replication-deficient recombinant human type 5 adenovirus with Escherichia coli $\beta$-galactosidase cDNA (Ad5LacZ) in the E3 region was constructed in a similar way. Virus was purified by $\mathrm{CsCl}$ gradient centrifugation and dialysed against autoclaved Tris- $\mathrm{HCl}$ buffer, pH 7.4, containing $10 \%$ glycerol.

\section{Establishment of brain infection}

Adult BALB/c mice, 8-12 weeks old, were obtained from the Sir William Dunn School of Pathology (Oxford University). Animals were anaesthetized with avertin $(0.1 \mathrm{ml} / 5 \mathrm{~g}$ body weight of $1.25 \%$ $\mathrm{wt} / \mathrm{vol}$ tribromoethanol in $2.5 \% \mathrm{vol} / \mathrm{vol}$ amyl alcohol) and atropine $(0.6 \mu \mathrm{g} / \mathrm{g}$ body weight). The animals were held in a stereotaxic apparatus and $0.5 \mu \mathrm{l}$ of Ad5LacZ or Ad5MIP-2, at doses ranging from $10^{4}$ to $10^{7}$ plaque-forming units (p.f.u.) per $0.5 \mu \mathrm{l}$, was injected in endotoxin-free phosphate-buffered saline into the dorsal hippocampus. Injections were made with finely drawn glass micropipettes at the stereotaxic coordinates: bregma -2.5, lateral 1.8 and depth $1.5 \mathrm{~mm}$. Monastral blue (Sigma) was included as an inert tracer. Animals were left for 2, 4, 7 or 14 days before they were deeply anaesthetized and killed by perfusion. See Table 1 for numbers of animals used.

\section{Assessment of blood-brain barrier permeability}

Animals were injected intravenously with $3 \mathrm{mg}$ (510 units) of horseradish peroxidase (type II; Sigma) in $100 \mu \mathrm{l}$ of $0.9 \%$ (wt/vol) saline $20 \mathrm{~min}$ before perfusion fixation. Using a cryostat, $50 \mu \mathrm{m}$ sections were cut through the injection site and peroxidase activity in the brain was detected using a modified Hanker-Yates method (Perry and Linden, 1982)

\section{Tissue preparation}

Mice were deeply anaesthetized with avertin and transcardial perfusion was initiated with heparinized saline followed by fixative containing $2 \%$ paraformaldehyde-lysine-periodate (McLean and
TABle 1. Animal numbers and survival times following Ad5MIP-2 or Ad5LacZ injection

\begin{tabular}{llllll}
\hline \multicolumn{5}{c}{ Days after adenovirus injection } \\
\cline { 2 - 6 } & p.f.u./0.5 $\mu \mathrm{l}$ & 2 days & 4 days & 7 days & 14 days \\
\hline Ad5LacZ & $10^{4}$ & 2 & & & \\
& $10^{5}$ & 2 & & & \\
& $10^{6}$ & 2 & & 2 & 2 \\
Ad5MIP-2 & $10^{7}$ & 4 & 2 & 4 & \\
& $10^{4}$ & 2 & & & \\
& $10^{5}$ & 2 & & 2 & \\
& $10^{6}$ & 2 & & 2 & 2 \\
\hline
\end{tabular}

Nakane, 1974) and $0.05 \%$ glutaraldehyde. The tissue was postfixed for a further $4-6 \mathrm{~h}$ in the same fixative at $4^{\circ} \mathrm{C}$. For cryoprotection, tissue was left overnight in $25 \%$ sucrose in phosphate-buffered saline before embedding in Tissue Tek OCT (Miles) and being rapidly frozen in liquid nitrogen. Sections $(10 \mu \mathrm{m})$ were cut using a cryostat and were air-dried.

\section{Immunohistochemistry and leukocyte identification}

Antigens expressed by the different leukocyte populations were localized by immunohistochemistry using the following primary antibodies. Expression of transgene product was assessed using a rabbit polyclonal antibody against $\beta$-galactosidase (a gift from Dr M. Wood) and a rabbit polyclonal antibody against murine MIP2 previously characterized by Dr S. L. Kunkel (Lucas et al., 1995). Macrophages were identified using F4/80, a rabbit polyclonal antibody against a $160 \mathrm{kDa}$ membrane glycoprotein expressed by most tissue macrophages (Austyn and Gordon, 1981), and TIB120 rat monoclonal against major histocompatibility complex (MHC) class II (Bhattacharya et al., 1981). Resident microglia were distinguished from macrophages by their ramified appearance. PMNs were identified by their polylobed nuclei stained with cresyl violet and the monoclonal antibody TIB122 against the leukocyte common antigen (Springer et al., 1978). The term 'polymorphonuclear leukocyte' is synonymous with the term 'neutrophil'. We cannot exclude the presence of rare eosinophilic and basophilic granulocytes in the infiltrates to the CNS parenchyma. CD4- and CD8-positive lymphocytes were identified using monoclonal antibodies YTS 191.1 and YTS 169.4 respectively (Cobbold et al., 1984). Endothelial activation was detected using a rat monoclonal antibody against murine intercellular cell adhesion molecule-1 (ICAM-1) (Takei, 1985; Horley et al., 1989). The tissue was incubated with the primary antibody for $90 \mathrm{~min}$ at room temperature. Antibody binding was detected using the avidin-biotin peroxidase method with diaminobenzidine as the chromogen (Hsu et al., 1981). Non-specific Fc binding was prevented by preincubation with normal serum and non-specific peroxidase activity eliminated by the glucose oxidase method (Locksley et al., 1983). Control sections were treated in the same way, omitting incubation with the primary antibody.

\section{Results}

\section{Ad5LacZ injection caused minimal brain inflammation}

Ad5LacZ injections were carried out to examine the inflammatory response mounted against the virus. We could then determine the contribution made by MIP-2 to the inflammatory response following 


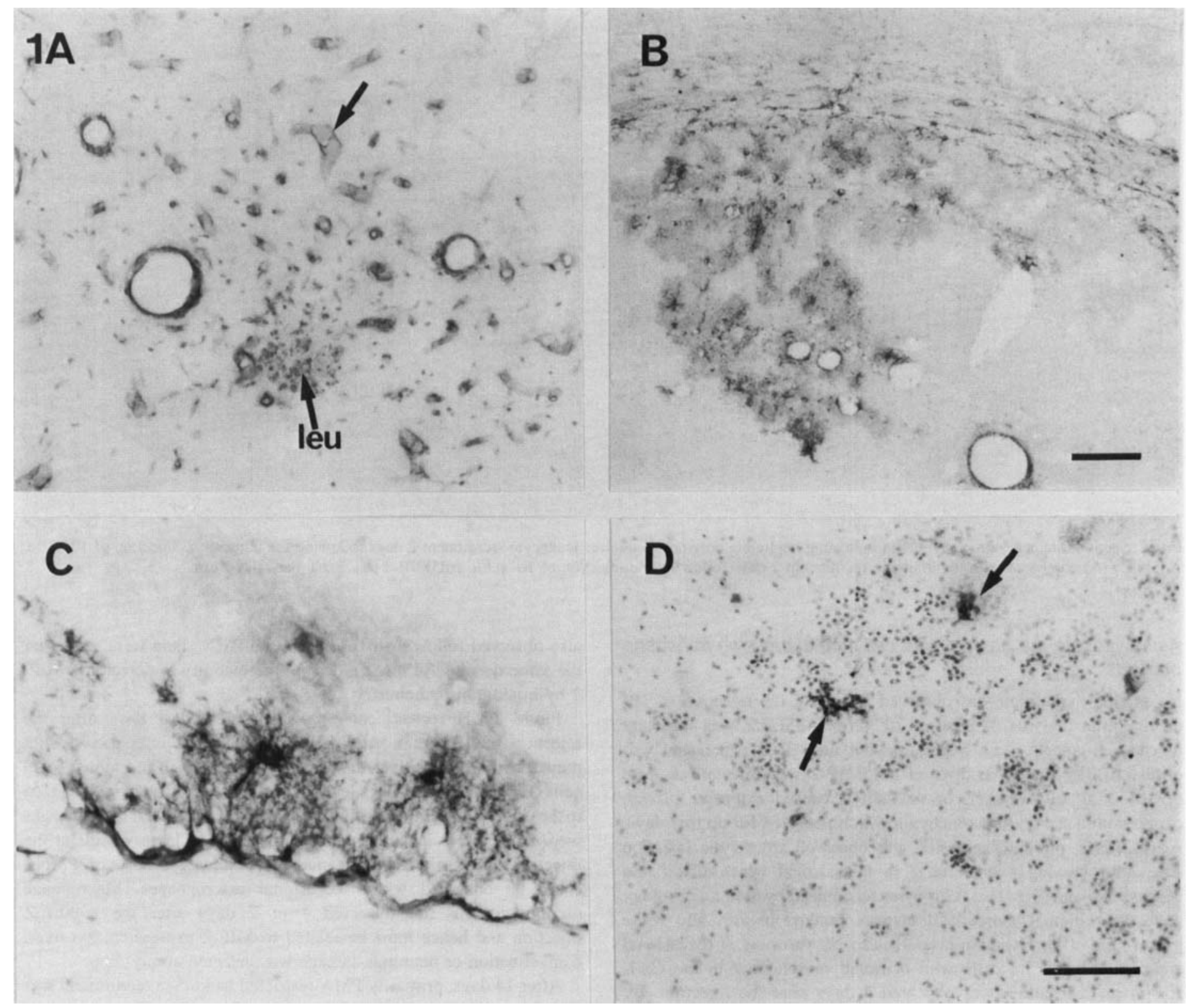

FIG. 1. Micrographs showing CNS response and protein expression after the intracranial injections of $10^{7}$ p.f.u. of Ad5LacZ or Ad5MIP-2. (A) Staining with anti-ICAM-1 antibody 2 days after the intracranial injection of Ad5LacZ indicates widespread ICAM-1 up-regulation on the endothelium (arrow). Note minimal leukocyte recruitment, which is restricted to the injection site (leu). (B, C) Staining with anti- $\beta$-galactosidase. Expression of $\beta$-galactosidase is widespread in the injected hippocampus (B) and is especially clear on cells with astrocyte-like morphology (C). (D) MIP-2 expression detected with anti-murine MIP-2 antibody 7 days following the intracranial injection of $10^{7}$ p.f.u. Ad5MIP-2. Note expression by astrocyte-like cells (arrow) in the presence of dramatic polymorphonuclear leukocyte recruitment. Scale bar for $B=100 \mu \mathrm{m}$. Scale bar for $A, C$ and $D=50 \mu \mathrm{m}$.

Ad5MIP-2 injection. $\beta$-Galactosidase, the product of Ad5LacZ, does not elicit an inflammatory response (Byrnes et al., 1995).

At all doses, Ad5LacZ injection produced minimal leukocyte recruitment to the brain parenchyma and meninges (Fig. 1A). After 2 days, a dose of $10^{6}$ p.f.u. produced morphological up-regulation of microglia throughout the injected hippocampus. ICAM-1 expression on endothelium showed a similar distribution (Fig. 1A). At lower doses, activation of microglia and endothelium was restricted to the injection site. Injections of $10^{6}$ or $10^{7}$ p.f.u. of virus caused MHC class II expression on reactive microglia with a distribution similar to that for $\beta$-galactosidase expression. Rounded macrophages expressing MHC class II were confined to the injection site and meninges. Small numbers of CD4- and CD8-positive T-cells in about equal numbers were recruited to the injection site and meninges after $10^{6}$ and $10^{7}$ p.f.u. Small numbers of PMNs were only observed at the injection site following the highest dose. Leukocyte recruitment to the parenchyma 4 days after $10^{7}$ p.f.u. Ad5LacZ was similar to that observed after 2 days. Small numbers of macrophages, T-cells and PMNs were observed at the injection site and in the meninges.

By 7 days, occasional T-cells still remained in the parenchyma and meninges. Microglia had returned to their resting phenotype except in the injection tract, and the endothelium no longer expressed ICAM-1. No overt cytopathic effects of the virus were detected at any time point. 


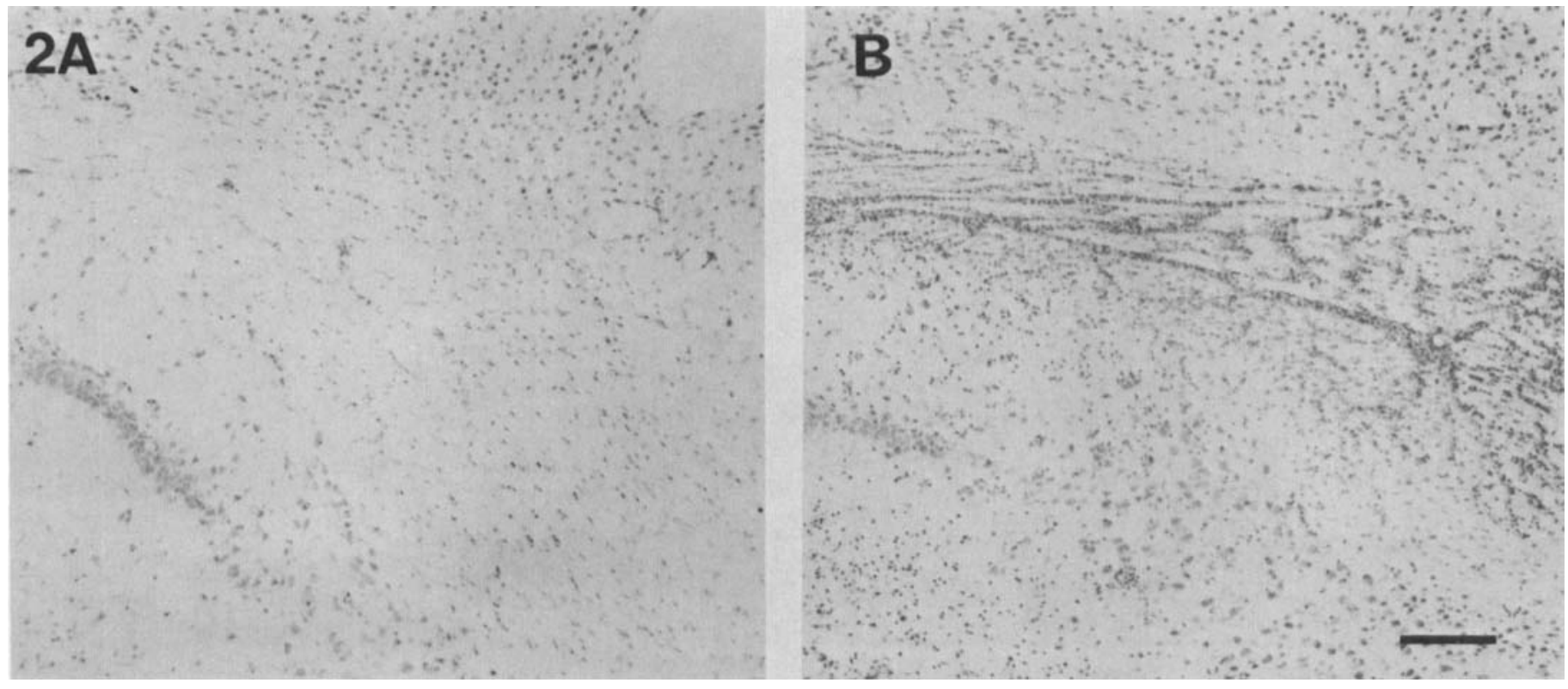

FIG. 2. Sections stained with cresyl violet indicating negligible polymorphonuclear leukocyte recruitment 2 days following the intracranial injection of $10^{7}$ p.f.u. Ad5LacZ (A) compared with the dramatic recruitment 2 days following the injection of $10^{7}$ p.f.u. Ad5MIP-2 (B). Scale bar $=100 \mu \mathrm{m}$.

\section{Astrocytes are the predominant cell type expressing transgene products}

No protein expression was observed following the injection of $10^{4}$ or $10^{5}$ p.f.u. of virus. A dose of $10^{6}$ p.f.u. Ad5LacZ was sufficient to cause $\beta$-galactosidase expression but no MIP-2 expression was observed after the same dose of Ad5MIP-2 was injected. A dose of $10^{7}$ p.f.u. of Ad5LacZ or Ad5MIP-2 caused extensive protein expression in the brain parenchyma which persisted for up to 7 days. After 2 days, protein expression was observed around the injection site and following axonal tracts in the cortical white matter and corpus callosum (Fig. 1B). Astrocytes recognized by their morphology were the principal source of transgene product in grey and white matter (Fig. 1C). Expression could also be observed on occasional endothelial cells and cells with neuronal morphology in the CA1. A similar distribution was observed 4 days after the injection. By 7 days, the same cell types were observed to express protein but expression was localized to the injection site. Expression of $\beta$ galactosidase was still detected at the injection site 14 days after Ad5LacZ injection. MIP-2 expression following Ad5MIP-2 injection was, after the same time, restricted to rare glial processes around the injection site. At earlier time points MIP-2 expression was associated with PMN recruitment (Fig. 1D).

\section{PMN recruitment in response to Ad5MIP-2 brain infection}

At all doses, the microglial activation 2 days following Ad5MIP-2 injection cells was similar to that observed after Ad5LacZ injection, as was the endothelial ICAM-1 expression and the recruitment of T-cells. Whereas the Ad5LacZ caused minimal PMN recruitment (Fig. 2A), a dose of $10^{7}$ Ad5MIP-2 elicited extensive PMN recruitment after 2 days (Figs $2 \mathrm{~B}$ and $3 \mathrm{~A}$ ). PMNs were present in the white matter and the dendritic fields of the CA1 pyramidal cells, and were observed cuffing large vessels in the hippocampal fissure. PMN recruitment was associated with MIP-2 expression. Few PMNs were observed in the meninges and there was no evidence of choroiditis. Numerous fragmented nuclei and pyknotic cells were also detected, indicating dying PMNs. Low numbers of PMNs were also observed following $10^{6}$ p.f.u. (more PMNs than were seen after the same dose of Ad5LacZ), despite the inability to detect any MIP2 by immunohistochemistry.

Florid PMN recruitment was still observed 4 days after the injection of $10^{7}$ p.f.u. Ad5MIP-2. PMNs were interspersed with numerous $\mathrm{F} 4 / 80$-positive round macrophages which resembled foam cells (Fig. 3B). After 7 days leukocyte recruitment was more localized to the original injection site (Fig. 3C). Heal thy PMNs and macrophages were still present in large numbers surrounding large vessels at the injection site itself. Pyknotic nuclei, presumably those of PMNs, could be observed within occasional macrophages. Macrophage recruitment was not observed 4 or 7 days after the Ad5LacZ injection and hence must be related to MIP-2 expression. No overt demyelination or neuronal damage was detected at any time.

After 14 days, primarily PMN restricted leukocyte recruitment was still detected around the injection site (Fig. 3D). The number of recruited cells was much reduced from 7 days.

\section{Leukocyte recruitment following Ad5MIP-2-2 injection was associated with breaching of the blood-brain barrier}

A dose of $10^{7}$ p.f.u. Ad5LacZ produced breakdown of the bloodbrain barrier (BBB) that was largely restricted to the injection site (Fig. 4A). In contrast, a similar dose of Ad5MIP-2 produced extensive breakdown of the BBB after 2 days. (Fig. 4B). Horseradish peroxidase and IgG could be localized to areas of PMN recruitment. This breakdown was prolonged since it was still evident after 7 days (Fig. $4 C$ ), but by 14 days (Fig. 4D) it was restricted to the original injection site.

\section{Discussion}

In the present study we have used an adenoviral transgene system to explore the biological effect of continuous MIP-2 expression in the brain. Doses ranging from $10^{4}$ to $10^{7}$ p.f.u. of Ad5LacZ and Ad5MIP-2 were injected into the dorsal hippocampus and immunohistochemistry was used to investigate the inflammatory response. 


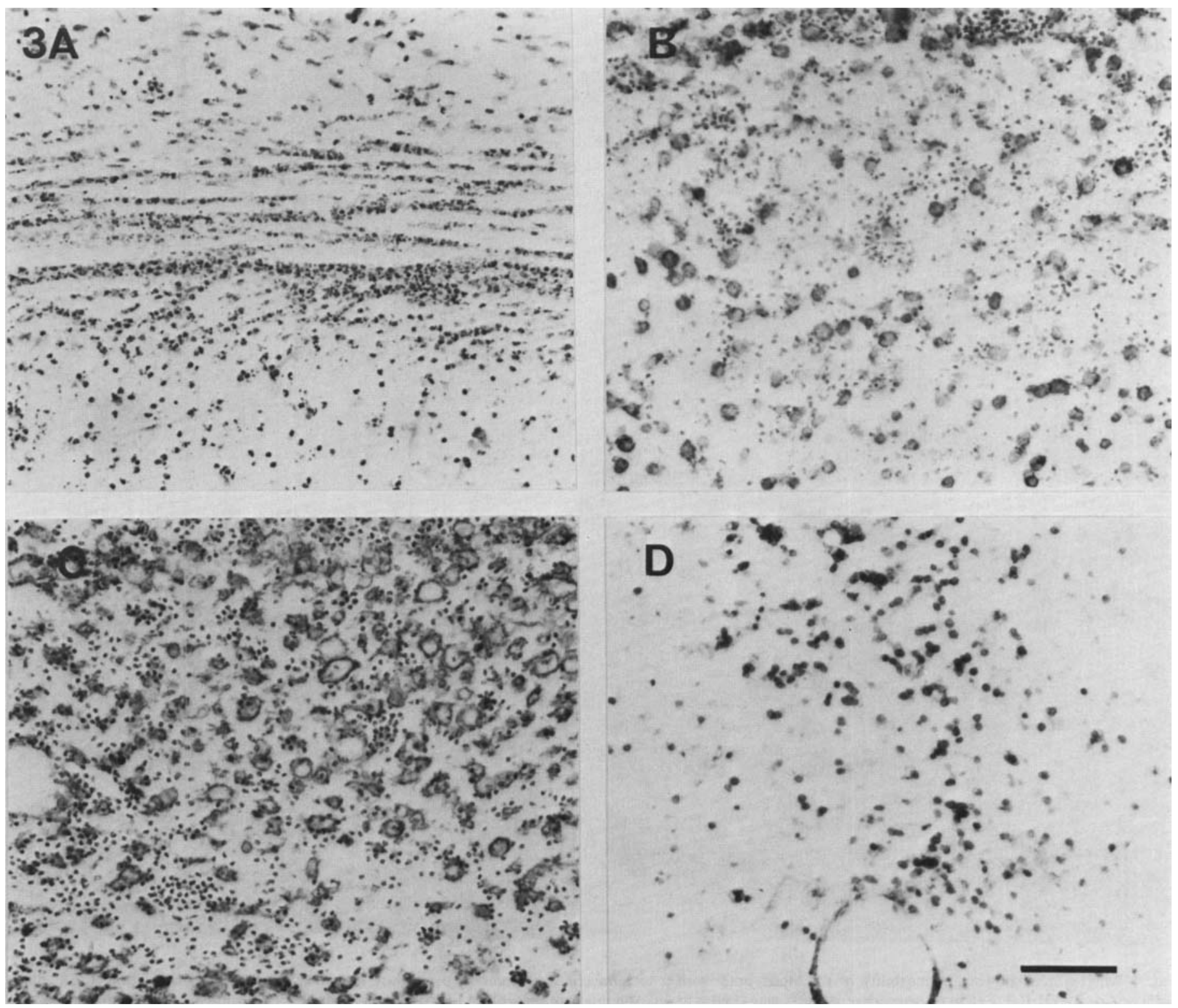

FIG. 3. Micrographs showing leukocyte recruitment following the intracranial injection of $10^{7}$ p.f.u. Ad5MIP-2. After 2 days, staining with cresyl violet indicates dramatic polymorphonuclear leukocyte recruitment, especially in the white matter (A). After 4 days (B) and 7 days (C), staining with F4/80 polyclonal antibody reveals numerous recruited macrophages interspersed with polymorphonuclear leukocytes. After 14 days, polymorphonuclear leukocyte recruitment is still observed at the injection site shown in D with anti-leukocyte common antigen staining. Scale bar $=50 \mu \mathrm{m}$.

An intracranial injection of $\mathrm{Ad} 5 \mathrm{LacZ}$ at $10^{7}$ p.f.u. caused microglial activation but minimal leukocyte recruitment to the brain parenchyma. Both vectors were mainly targeted to astrocytes, which expressed high levels of the transgene products for at least 7 days following the injection. Whereas Ad5LacZ infection resulted in negligible PMN recruitment, Ad5MIP-2 resulted in dramatic PMN recruitment to the brain parenchyma after 2 days. Surprisingly, PMN recruitment persisted after 4 and 7 days but had become more localized to the injection site and was associated with numerous foam-like macrophages. Breakdown of the BBB was restricted to the injection site following Ad5LacZ injection, but following the Ad5MIP-2 injection BBB breakdown was dramatic in areas of leukocyte infiltration at both 2 and 7 days.

\section{The CNS inflammatory response to virus}

One caveat that arises from adenovirus gene transfer into tissue is the host inflammatory or immune response mounted against the virus. This may influence the biological effect of the transgene products under study and make interpretation difficult. In the CNS, this may be less of a problem given the relatively down-regulated nature of inflammatory and immune responses when compared with those in non-CNS tissues. In other tissues, both cellular and humoral immune responses have been described in response to adenovirus injection (Yang et al., 1994). The more prolonged expression in neonates and immunosuppressed adults indicates that the immune response contributes to the limited duration of transgene product expression (Kass-Eisler et al., 1994; Yang et al., 1994). Within the CNS, we and other laboratories have reported that 


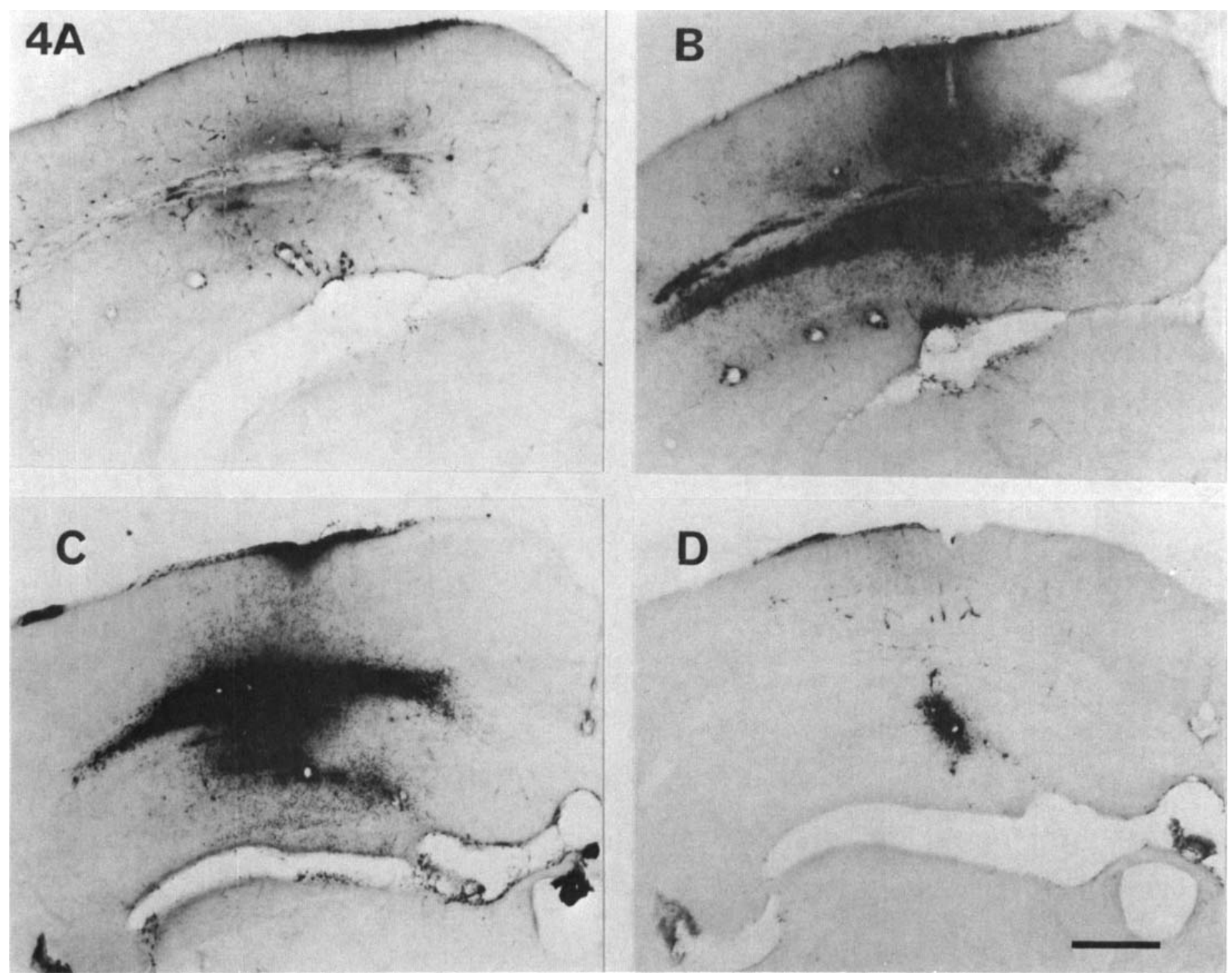

FIG. 4. Micrographs showing permeability of the blood-brain barrier to intravenous horseradish peroxidase following the intracranial injection of $10^{7}$ p.f.u. Ad5LacZ or Ad5MIP-2. Extent of peroxidase staining was similar to IgG staining (not shown). (A) Blood-brain barrier breakdown was restricted to the injection site 2 days following Ad5LacZ. (B) Blood-brain barrier breakdown was more extensive 4 days after Ad5MIP-2. Breakdown was still observed after 7 days (C) and by 14 days was restricted to the injection site (D). Scale bar $=500 \mu \mathrm{m}$.

the inflammatory response is minimal in the CNS with microglial activation but negligible leukocyte recruitment (Andersson et al., 1991, 1992a, b; Le Gal La Salle et al., 1993; Horellou et al., 1994). This may be one reason for the prolonged expression, for up to 2 months, of transgene products in the CNS (Davidson et al., 1993; Byrnes et al., 1995). Strain differences must be borne in mind, given a recent study that detailed the inflammatory response to Ad5LacZ injection in rat brain. The severity of the inflammatory response was found to depend on the strain of rat used (Byrnes et al., 1995). In the current study, the inflammatory response produced following infection with Ad5MIP-2 could be almost solely attributed to expression of the MIP-2 protein.

\section{Transgene product expression}

The cell types that are infected and express the transgene products are an important consideration when investigating the function of chemokines in vivo. Ideally, the adenovirus would be targeted to the natural producers of chemokines during inflammation. In experimental allergic encephalomyelitis, astrocytes appear to be the principal source of the chemokines monocyte chemotactic protein-1 and interferon$\gamma$-inducible protein within the CNS parenchyma (Ransohoff et al., 1993). To further validate this model, MIP-2 appeared to be preferentially expressed by astrocytes. It is unclear whether this expression represents newly synthesized protein or protein that has persisted. This may be important as chemokine remaining bound to extracellular matrix proteins may still be able to exert a chemotactic effect. Studies in non-CNS tissues indicate that mRNA synthesis for transgenes transferred by adenovirus vectors can continue for weeks. Human cystic fibrosis transporter (CFTR) mRNA transcripts were still expressed at significant levels 6 weeks after in vivo Ad-CFTR infection of cotton rat airway epithelium (Rosenfeld et al., 1992). 


\section{Continuous MIP-2 production versus single MIP-2 injection}

Single intracranial injections of a long list of proinflammatory agents, including lipopolysaccharide, f-met-leu-phe, platelet-activating factor, IL-1 and tumour necrosis factor, provoke minimal PMN recruitment to the brain parenchyma when compared with non-CNS tissue sites (Andersson et al., 1992a, b). Extremely high, non-physiological doses of lipopolysaccharide are required to provoke PMN recruitment to the parenchyma. MIP-2 is a powerful PMN chemoattractant in vivo and in vitro (Wolpe et al., 1989; Wolpe and Cerami, 1989), and murine recombinant MIP-2 and human recombinant IL-8 (M. D. Bell, D. D. Taub and V. H. Perry, submitted for publication) are the only agents tested that are capable of overriding this resistance. A single injection of $1 \mu \mathrm{g}$ MIP-2 into the murine dorsal hippocampus is sufficient to evoke extensive meningitis and PMN recruitment into the brain parenchyma with BBB breakdown. Peak PMN recruitment is observed after $24 \mathrm{~h}$ and is substantially reduced by 2 days. In the current study, we have demonstrated that transient but prolonged expression of MIP-2 is a similarly powerful stimulus for PMN recruitment.

A single injection of recombinant MIP-2 is likely to diffuse over a large distance, and drainage into the CSF may account for the extensive meningitis that is observed. The brain parenchyma is not so permissive for adenovirus diffusion and so the cell types infected remain adjacent to the injection site (Akli et al., 1993). In this instance the MIP-2 expressed by infected astrocytes exerts a more local effect than the single injections, with PMN recruitment only observed where transgene product is expressed. Given the propensity for chemokines to bind negatively charged glycosaminoglycans (Tanaka, 1993), it is likely that MIP-2 is sequestered by the surrounding extracellular matrix and remains associated with the cells that synthesize it. This will ensure that the inflammatory response does not extend into other tissue areas unnecessarily.

\section{Tachyphylaxis did not occur in response to continuous MIP-2 production}

Rapid tachyphylaxis of the brain microenvironment is one mechanism proposed to account for the minimal recruitment of PMNs during brain inflammation. PMNs are particularly prone to desensitization (Ward and Becker, 1968) and repeated exposure to chemotactic agonists in vitro results in a decline in responsiveness (for review see Colditz, 1991). Within tissues, this can quickly lead to the termination of PMN infiltration. In the past, tachyphylaxis has been examined by multiple injections into the same tissue site. This is unlikely to replicate events during tissue damage or infection, when proinflammatory mediators are produced continuously for prolonged periods of time. Adenovirus gene transfer is a more physiological way in which to investigate desensitization phenomena. Single injections of MIP-2 into the brain result in transient PMN recruitment that wanes after $48 \mathrm{~h}$. This transient nature of the PMN recruitment is similar to that observed in non-CNS tissues with other chemotactic agonists (for review see Colditz, 1991). The MIP-2 may be quickly dispersed and PMN-derived chemoattractant products are not sufficient to maintain PMN recruitment at its previous level. It was perhaps surprising that, with continuous MIP-2 expression, PMN infiltration was still observed 7 days after the initial adenovirus injection. PMN recruitment was not as dramatic as after $48 \mathrm{~h}$ but was restricted to sites exposed to higher titres of virus at the injection site. The absence of PMN recruitment at sites where it had been previously observed was not likely to be due to desensitization but rather to the loss of transgene product. Densensitization of the plasma leakage response to agents such as histamine and bradykinin has been observed in guinea-pigs and humans (Lewis and Grant, 1924; Miles and Miles, 1952; Greaves and Shuster, 1967; Baumgarten et al., 1970). We have previously demonstrated that MIP-2-induced breakdown of the BBB is leukocyte-dependent. The breakdown of the BBB after 7 days would indicate that there is no desensitization in response to the granulocyte-derived products responsible for this.

\section{PMNs and tissue damage}

Many studies have documented the contribution made by the products of PMN activation to tissue damage (for review see Weiss, 1989). Accumulation of PMNs in the cerebral circulation during models of ischaemia-reperfusion injury and cerebral malaria is instrumental in causing increases in BBB permeability (Kochanek and Hallenbeck, 1992; Senaldi et al., 1994). Studies investigating the effects of PMN activation on myelin or neurons are scarce. Products of the PMN respiratory burst, such as oxygen free radicals, have been shown to be toxic to spinal cord neurons in culture (Michikawa et al., 1994). Furthermore, studies in vitro indicate that excitatory amino acids may be released in response to oxygen radicals (for review see Halliwell, 1989). In this instance, prolonged PMN recruitment results in disruption of the BBB, but there were no signs of overt demyelination or neuronal degeneration. MIP-2 does elicit a respiratory burst in PMNs, although it is not as powerful a stimulus as IL-8 (Wolpe et al., 1989), but it is unknown whether the PMNs are activated within the brain parenchyma.

\section{Specificity of MIP-2 for PMN recruitment is lost with time}

After 7 days, the specificity of the response for PMNs is lost with the appearance of foam-like macrophages in the region of MIP-2 expression. Whether this is a response to PMN death, PMN-derived monocyte chemoattractants or subtle tissue damage not detected by light microscopy remains to be elucidated. PMN recruitment on its own may be sufficient to drive monocyte recruitment, and hence the absence of PMN recruitment during acute neuronal degeneration, for example, may be partially responsible for the delayed monocyte recruitment. The use of selective antibodies to PMNs would allow us to determine whether the macrophage recruitment seen after Ad5MIP-2 was dependent on prior PMN recruitment.

\section{Conclusion}

We have demonstrated that the transfection of brain glial cells with an adenovirus expressing rat MIP-2 results in prolonged MIP-2 expression. PMNs are recruited to the brain parenchyma over an extended period of time with little evidence of desensitization. The exclusion of PMNs from the brain parenchyma following various forms of brain injury may indicate a deficiency in the production of PMN chemoattractants.

\section{Acknowledgements}

This work was funded by the Multiple Sclerosis Society and The Wellcome Trust. V. H. P. is a Wellcome Trust Senior Research Fellow.

\section{Abbreviations}

Ad5LacZ human type 5 adenovirus with $L a c Z$ gene insertion Ad5MIP-2 human type 5 adenovirus with rat $M I P$-2 gene insertion BBB blood-brain barrier

ICAM-1 intercellular cell adhesion molecule-1

IL

major histocompatibility complex

MIP-2 macrophage inflammatory protein-2 
p.f.u. plaque-forming unit

PMN polymorphonuclear leukocyte

\section{References}

Addison, C. L., Braciak, T., Ralston, R., Muller, W. J., Gauldie, J. and Graham, F. L. (1995) Intra-tumoral injection of an adenovirus expressing interleukin- 2 induces regression and immunity in a murine breast cancer model. Proc. Natl Acad. Sci. USA, in press.

Akli, S., Caillaud, C., Vigne, E., Stratford-Perricaudet, L. D., Poenaru, L., Perricaudet, M., Kahn, A. and Peschanski, M. R. (1993) Transfer of a foreign gene into the brain using adenovirus vectors. Nature Genet., 3 , 224-228.

Andersson, P. B., Perry, V. H. and Gordon, S. (1991) The kinetics and morphological characteristics of the macrophage-microglial response to kainic acid-induced neuronal degeneration. Neuroscience, 42, 201-214.

Andersson, P. B., Perry, V. H. and Gordon, S. (1992a) The acute inflammatory response to lipopolysaccharide in CNS parenchyma differs from that in other body tissues. Neuroscience, 48, 169-186.

Andersson, P. B., Perry, V. H. and Gordon, S. (1992b) Intracerebral injection of proinflammatory cytokines or leukocyte chemotaxins induces minimal myelomonocytic cell recruitment to the parenchyma of the central nervous system. J. Exp. Med., 176, 255-259.

Austyn, J. M. and Gordon, S. (1981) F4/80, a monoclonal antibody directed specifically against the mouse macrophage. Eur. J. Immunol., 11, 805-815.

Bajocchi, G., Feldman, S. H., Crystal, R. G. and Mastrangeli, A. (1993) Direct in vivo gene transfer to ependymal cells in the central nervous system using recombinant adenovirus vectors. Nature Genet., 3, 229-234.

Baumgarten, A., Melrose, G. J. H. and Vagg, W. J. (1970) Interactions between histamine and bradykinin assessed by continuous recording of increased vascular permeability. J. Physiol. (Lond.), 208, 669-675.

Bhattacharya, A., Dorf, M. E. and Springer, T. A. (1981) A shared alloantigenic determinant on I-A and I-E subregions: evidence for I region gene duplication. J. Immunol., 127, 2488-2495.

Braciak, T. A., Mittal, S. K., Graham, F. L., Richards, C. D. and Gauldie, J. (1993) Construction of recombinant human type-5 adenoviruses expressing rodent IL-6 genes-an approach to investigate in vivo cytokine function. J. Immunol., 151, 5145-5153.

Bymes, A. P., Rusby, J. E., Wood, M. J. A. and Charlton, H. M. (1995) Adenovirus gene transfer causes inflammation in the brain. Neuroscience, 66, 1015-1024.

Cobbold, S. P., Jayasuriya, A., Nash, A., Prospero, T. D. and Waldmann, H. (1984) Therapy with monoclonal antibodies by elimination of T-cell subsets in vivo. Nature, 312, 548-551.

Colditz, I. G. (1991) Desensitisation mechanisms regulating plasma leakage and neutrophil emigration. In Gordon, J. (ed.), Vascular Endothelium. Interactions with Circulating Cells. Elsevier Science Publishers, Amsterdam, pp. $175-187$

Davidson, B. L., Allen, E. D., Kozarsky, K. F., Wilson, J. M. and Roessler, B. J. (1993) A model system for in vivo gene transfer into the central nervous system using an adenoviral vector. Nature Genet., 3, 219-223.

Driscoll, K. E., Hassenbein, D., Howard, B. W., Isfort, R. J., Cody, D., Tindal, M. H., Suchanek, M. and Carter, J. M. (1995) Cloning, expression and functional characterisation of rat MIP-2: a neutrophil chemoattractant and epithelial cell mitogen. J. Leuk. Biol., 58, 359-364.

Greaves, M. and Shuster, S. (1967) Responses of the skin blood vessels to bradykinin, histamine and 5-hydroxytryptamine. J. Physiol. (Lond.), 193, 255-267.

Halliwell, B. (1989) Oxidants and the central nervous system: some fundamental questions. Acta Neurol. Scand., 126, 23-33.

Herz, J. and Gerard, R. D. (1993) Adenovirus-mediated transfer of low density lipoprotein receptor gene acutely accelerates cholesterol clearance in normal mice. Proc. Natl Acad. Sci. USA, 90, 2812-2816.

Horellou, P., Vigne, E., Castel, M. N., Barneoud, P., Colin, P., Perricaudet, M., Delaere, P. and Mallet, J. (1994) Direct intracerebral gene transfer of an adenoviral vector expressing tyrosine hydroxylase in a rat model of Parkinson's disease. NeuroReport, 6, 49-53.

Horley, K. J., Carpenito, C., Baker, B. and Takei, F. (1989) Molecular cloning of murine intercellular adhesion molecule (ICAM-1). EMBO J., 8, 2889-2896.

Hsu, S. M., Raine, L. and Fangier, H. (1981) The use of avidin-biotinperoxidase $(\mathrm{ABC})$ complex in immunoperoxidase techniques: a comparison between $\mathrm{ABC}$ and unlabelled antibody (PAP) procedures. J. Histochem. Cytochem., 29, 577-580.

Itagaki, S., McGeer, P. L. and Akiyama, H. (1988) Presence of T-cytotoxic suppressor and leucocyte common antigen positive cells in Alzheimer's disease brain tissue. Neurosci. Lett., 91, 259-264.

Jaffe, H. A, Danel, C., Longenecker, G., Metzger, M., Setoguchi, Y., Rosenfeld, M. A., Gant, T. W., Thorgeirsson, S. S., Stratford-Perricaudet, L. D. and Perricaudet, M. (1992) Adenovirus-mediated in vivo gene transfer and expression in normal rat liver. Nature Genet., 1, 372-378.

Kass-Eisler, A., Falck-Pedersen, E., Elfenbeim, D. H., Alvira, M., Buttrick, P. M. and Leinwand, L. A. (1994) The impact of developmental stage, route of administration and the immune system on adenovirus-mediated gene transfer. Gene Therapy, 1, 395-402.

Kochanek, P. M. and Hallenbeck, J. M. (1992 Polymorphonuclear leukocytes and monocytes/macrophages in the pathogenesis of cerebral ischemia and stroke. Stroke, 23, 1367-1379.

Le Gal La Salle, G., Robert, J. J., Berrard, S., Ridoux, V., Stratford-Perricaudet, L. D., Perricaudet, M. and Mallet, J. (1993) An adenovirus vector for gene transfer into neurons and glia in the brain. Science, 259, 988-990.

Lemarchand, P., Jaffe, H. A., Danel, C., Cid, M. C., Kleinman, H. K., Stratford-Perricaudet, L. D., Perricaudet, M., Pavirani, A., Lecocq. J. and Crystal, R. G. (1992) Adenovirus-mediated transfer of a recombinant human a I-antitrypsin cDNA to human endothelial cells. Proc. Natl Acad. Sci. USA 89, 6482-6488.

Lewis, T. and Grant, R. T. (1924) Vascular reactions of the skin to injury. Blood, 11, 209-265.

Locksley, R. M., Wilson, C. B. and Klebanoff, S. J. (1983) Increased respiratory burst in myeloperoxidase-deficient monocytes. Blood, 62. 902-909.

Lucas, N. W., Strieter, R. M., Standiford, T. J. and Kunkel, S. J. (1995) Characterisation of chemokine function in animal models of disease Immunomethods, in press.

McGeer, P. L., Walker, D. G.. Akiyama, H., Yasuhara, O. and McGeer, E. G. (1994) Involvement of microglia in Alzheimer's disease. Neuropathol. Appl. Neurobiol., 20, 191-192.

McLean, I. W. and Nakane, P. K. (1974) Periodate-lysine-paraformaldehyde fixative. A new fixation for immunoelectron microscopy. $J$. Histochem. Cytochem., 22, 1077-1083.

Michikawa, M., Lim, K. T., McLarnon, J. G. and Kim, S. U. (1994) Oxygen radical-induced neurotoxicity in spinal cord neuron cultures. $J$. Neurosci. Res., 37, 62-70.

Miles, A. A. and Miles, E. M. (1952) Vascular reactions to histamine, histamine liberator and leukotaxine in the skin of guinea-pigs. J. Physiol. (Lond.), 118, 228-257.

Perry, V. H. and Linden, R. (1982) Evidence for dendritic competition in the developing retina. Nature, 297, 683-685.

Quantin, B., Perricaudet, L. D., Tajbakhash, S. and Mandel, J. (1992) Adenovirus as an expression vector in muscle cells in vivo. Proc. Natl Acad. Sci. USA, 89, 2581-2584.

Ransohoff, R. M., Hamilton, T. A., Tani, M.., Stoler, M. H., Shick, H. E., Major, J. A., Estes, M. L., Thomas, D. M. and Tuohy, V. K. (1993) Astrocyte expression of mRNA encoding cytokines IP-10 and JE/MCP-1 in experimental autoimmune encephalomyelitis. FASEB J., 7, 592-600.

Rosenberg, M. B., Friedmann, T., Robertson, R. C., Tuszynski, M., Wolff, J. A., Breakefield, X. O. and Gage, F. H. (1988) Grafting genetically modified cells to the damaged brain: restorative effects of NGF expression. Science, 242, 1575-1577.

Rosenfeld, M. A., Yoshimura, K., Trapnell, B. C., Yoneyama, K., Dalemans, W., Fukayama, M., Bargon, J., Stier, L. E., Stratford-Perricaudet, L. D., Perricaudet, M., Guggino, W. B., Pavirani, A., Lecocq, J. and Crystal, R. G. (1992) In vivo transfer of human cystic fibrosis transmembrane conductance regulator gene to the airway epithelium. Cell, 68, 143-155.

Senaldi, G., Vesin, C., Chang, R., Grau, G. E. and Piguet, P. F. (1994) Role of polymorphonuclear neutrophil leukocytes and their integrin CD I la (LFA1) in the pathogenesis of severe murine malaria. Infect. Immun., 62 , 1144-1149.

Springer, J., Galfre, G., Secher, D. S. and Milstein, C. (1978) Monoclonal xenogeneic antibodies to murine cell surface antigens: identification of novel leukocyte differentiation antigens. Eur. J. Immunol., 8, 539-551.

Stratford-Perricaudet, L. D., Makeh, I., Perricaudet, M. and Briand, P. (1992) Widespread long-term gene transfer to mouse skeletal muscles and heart. J. Clin. Invest., 90, 626-630.

Takei, F. (1985) Inhibition of mixed lymphocyte response by a rat monoclonal antibody to a novel murine lymphocyte activation antigen (MALA-2). J. Immunol., 134, 1403-1407.

Tanaka, Y., Adams, D. H. and Shaw, S. (1993) Proteoglycans on endothelial cells present adhesion-inducing cytokines to leukocytes. Immunol. Today, 14, 111-115. 
Traugott, U., Reinherz, E. L. and Raine, C. S. (1983) Distribution of T-cells, T-cell subsets and Ia-positive macrophages in lesions of different ages. J. Immunol., 4, 201-221.

Ward, P. A. and Becker, E. L. (1968) The desensitisation of rabbit neutrophils by chemotactic factors and the nature of the activable esterase. J. Exp. Med., 127, 693-709.

Weiss, S. J. (1989) Tissue destruction by neutrophils. N. Engl. J. Med., 320, 365-376.

Wolff, J. A., Fischer, L. J., Xu, L., Jinnah, H. A., Langlais, P. J., Iuvone, P. M., O'Malley, K. L., Rosenberg, M. B., Shimohama, S., Friedman, T. and Gage, F. H. (1989) Grafting fibroblasts genetically modified to produce L-dopa in a rat model of Parkinson's disease. Proc. Natl Acad. Sci. USA, 86, $9011-9014$.
Wolpe, S. D. and Cerami, A. 1989 Macrophage inflammatory proteins 1 and 2: members of a novel superfamily of cytokines. FASEB J., 3, 2565-2573.

Wolpe, S. D., Sherry, B., Juers, D., Davetelis, G., Yurt, S. and Cerami, A. (1989) Identification and characterization of macrophage inflammatory protein 2. Proc. Natl Acad. Sci. USA, 86, 612-616.

Xing, Z., Braciak, T., Jordana, M., Croitoru, K., Graham, F. L. and Gauldie, J. (1994) Adenovirus-mediated cytokine gene-transfer at tissue sitesoverexpression of IL-6 induces lymphocytic hyperplasia in the lung. $J$. Immunol., 153, 4059-4069.

Yang, Y., Nunes, F. A., Berencsi, K., Furth, E. E., Gonczol, E. and Wilson, J. M. (1994) Cellular immunity to viral antigens limits El-deleted adenoviruses for gene therapy. Proc. Natl Acad. Sci. USA, 91, 4407-4411. 